\title{
Software for calculating the optimum tilt angle of PV modules in different latitudes of the Southern hemisphere and solar plant sizing
}

\author{
Matheus M. Cabral ${ }^{1}$, Sofia. A. Lemes ${ }^{1}$, Marcelo E. de Oliveira ${ }^{1}$, Paulo H. A. Silva e Silva ${ }^{1}$ and Ghunter \\ P. Viajante ${ }^{1}$ \\ ${ }^{1}$ Núcleo de Pesquisas em Sistemas de Energia - NuPSE \\ Federal Institute of Education, Science and Technology of Goiás - IFG \\ Campus Itumbiara, Goiás (Brazil) \\ E-mail: matc150@hotmail.com, sofia.l@academico.ifg.edu.br, marcelo.oliveira@ifg.edu.br
}

\begin{abstract}
Through the development of photovoltaic technologies, the market related to this type of renewable energy grows constantly. In Brazil, the generated power through photovoltaic (PV) power stations approximates to $2.3 \mathrm{GW}$ representing $1.3 \%$ of the total Brazilian energy mix. To supply the public it is necessary to offer tools that facilitate consumer decision making or even the work of a solar farm designer. By analyzing the user's necessity, it is possible to determine that a great parcel needs a quick and simple response to help them with their questions, and programs that are already well established in the marketplace are complex for inexperienced users. For this reason, a software that calculates the best inclination for PV modules using the method proposed by Liu and Jordan in 1962 is developed. It also determines the number of modules that can be installed without any shading between arrays within a user-defined area. This calculation is possible through the standard dimensions provided by the module manufacturers and the solar height and declination study. Through a simple interface, the user quickly receives the optimum tilt angle of installation, the number of PV modules and the maximum generated power.
\end{abstract}

Key words. Renewable energy, PV modules, software, optimum tilt angle, shading.

\section{Introduction}

The reduction of fossil fuel reserves and increasing proenvironment concern creates a demand for alternative sources of energy, which grows exponentially each year. According to the International Energy Agency (IEA) solar $\mathrm{PV}$ power generation is estimated to have increased by more than $30 \%$ in 2018, to over $570 \mathrm{TWh}$, and by year 2030 it estimates that this number reaches almost 3300 TWh [1].

The SolarPower Europe states that the preference for solar over other technologies is due to the steep cost reduction curve. Solar power generation costs are significantly lower than for new nuclear and coal plants, and usually below gas and wind depending on the region. However, this technology is still expensive for developing countries [2]. In Brazil, although most of the energy mix is constituted of renewable energy [3] - predominantly hydropower - the demand for PV systems has shown exponential leaps due to the reduction of material prices, high-energy potential and good financial return. The installation shows an increase in energy efficiency and a reduction in electricity consumption from the energy utilities, behavior similarly reported by [4].

This ongoing situation represents an increase of consumers in this sector and, consequently, a diversification of the public. Thus, is created a new market: PV system software. In the complete ones, it is possible to calculate a preview of the generation with high precision, including losses, tariffs and weather conditions. However, to access all the functions that the software contain it is necessary to purchase a license.

The software developed in this paper offers the user simpler answers when compared to paid software. However, it meets the needs of the targeted audience: users that wants simple responses about the implementation of a solar farm.

The software, for each latitude, optimally dimensions the PV system. Therefore, it uses a method of predicting the solar irradiance incident on a flat terrestrial surface for calculating the optimal tilt angle. The study about this prediction is divided in methods that considers the solar irradiation scattered as uniform in all directions (isotropic) or variable to each direction (anisotropic).

Liu and Jordan [5] used the isotropic method for predicting the radiation upon solar-energy collectors through data about the daily radiation and developed a method for predicting its long-term performance. Latter, Klutcher [6], Temps and Coulson [7], and Perez, et al. [8] used the anisotropic method to further improve the prediction. Yadav and Chandel [9] then reviewed the majority of methods for predicting the radiation incident on a terrestrial flat surface.

The software uses the method described by Liu and Jordan [5]. It considers that the total irradiation on a terrestrial surface is the sum of the following irradiations:

- Direct irradiation: solar irradiation that directly reaches the module;

- Diffuse irradiation: solar irradiation that indirectly reaches the module. The solar radiation is scattered by the mean it is passing through (e.g. clouds, fog and suspended dust particles); 
- Albedo irradiation: rays that are reflected on objects or on the Earth ground.

Different methods were developed to calculate or determine the optimal tilt angle of installation [10 - 12]. However, this software applies a Particle Swarm Optimization (PSO) in order to decrease the conversion time to the optimum tilt angle number, by maximizing the average annual irradiation function.

The PSO is faster than conventional Genetic Algorithms [13] and shows higher errors when compared with the Hirschberg-Sinclair algorithm [14] but it is not a major problem to its purpose in this software.

Through the tilt angle number, the site characteristics and the module dimensions the software predicts the quantity of solar panels that fits in the area. It uses simple geometry for calculating the inter-row spacing in order to improve the solar farm efficiency.

Therefore, the software, with a user-friendly interface, receives site characteristics and returns the number of modules, the maximum generation in Watts (W) and the optimum tilt angle of installation focusing in the Southern hemisphere.

\section{Photovoltaic modules}

Despite being discovered in 1840 [15], the photovoltaic effect has only recently become viable with the growth of the renewable energy market, increased energy conversion efficiency and political incentive policies.

A definite advance on the development of PV power generation was the deployment of by-pass diodes. These diodes are placed in the module sub-strings, and each normally groups two photovoltaic cell lines.

According to [16], by-pass diodes are used for protection against mismatch and shading effects allowing current to flow through even if the module's cells are shaded or if a surge occurs.

Figure 1 shows the portrait and landscape modules, respectively. In the first one, there is a reduction of current in the module, because there is dust accumulation in all three sub-strings. In the second, only region 1 is affected due to the presence of diodes.

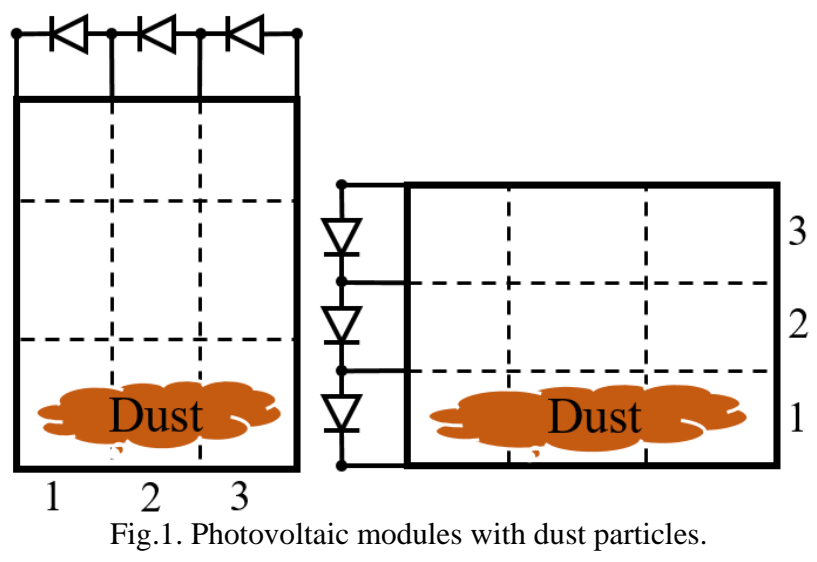

The software is configured to use landscape-oriented PV modules for the system optimization and the dimensions of the chosen model are 2108 X 1048 X $40 \mathrm{~mm}$ [17].

Si-crystalline (mono or poly) panes represent the most consolidated PV technology and have dominated the PV market over the past decades [18]. As a result, there are more efficient polycrystalline silicon modules such as the Canadian Solar HiKu 415W [17] - used in the calculations of this paper - which was the first polycrystalline module to exceed $400 \mathrm{~W}$.

The HiKu modules uses half-cell technology in which photovoltaic cells are reduced to half the size they would have on other models, thus reducing internal resistance and the Joule heating.

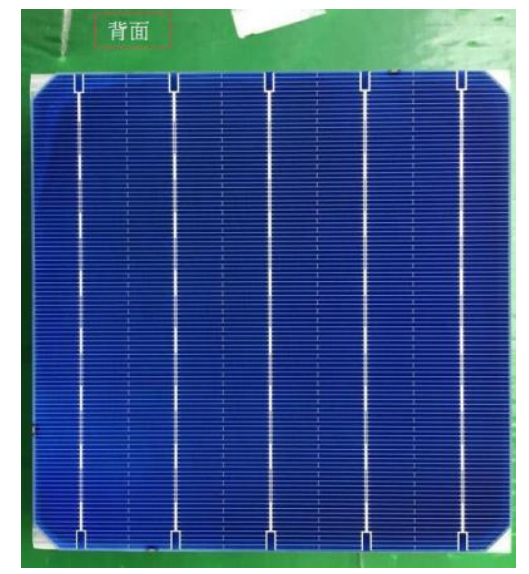

Fig.2. Photovoltaic cell with 5 busbar [18].

Therefore, this construction has $24 \%$ more power than conventional modules, up to $2,7 \%$ lower system cost, lower temperature coefficient $\left(-0,37 \% /{ }^{\circ} \mathrm{C}\right)$, better shadowing tolerance and lower cost [17]. In this paper, temperature effects are not taken into account on the development of the software.

\section{Sun trajectory and the irradiation on a terrestrial surface}

In order to have a higher power generation the modules are installed at a certain angle that receives the highest amount of average solar irradiation throughout the year.

The installation angle vary for several factors, the main ones being the latitude and hemisphere. For this, the trajectory of the sun and the irradiation during the days of the year are mathematically modeled in relation to a flat surface installed on the Earth.

\section{A. Sun trajectory}

Each day of the year is assigned a value (from the Julian Day Number), with January 1st being 1 and December 31 st related to 365 .

The sun angle in relation to the ground changes throughout the year and, according to [19], this behavior is represented by equation 1 .

$$
\delta=23,45 \cdot \sin \left(360 \cdot\left(\frac{284+J D N}{365}\right)\right)
$$

Which, JDN is the Julian Day Number and $\delta$ the declination angle.

For a higher precision $\delta$ is represented by equation 2 . 


$$
\begin{aligned}
\delta=0,006918- & 0,399912 \cos \alpha \\
& +0,070257 \sin \alpha \\
& +0,006758 \cos 2 \alpha \\
& +0,000907 \sin 2 \alpha \\
& -0,002697 \cos 3 \alpha \\
& +0,00148 \sin 2 \alpha
\end{aligned}
$$

Where, $\alpha$ is defined by equation 3 .

$$
\alpha=\frac{2 \pi \cdot(J D N-1)}{365}
$$

The solar time differs from the mean solar time (clock time). At each hour, $15^{\circ}$ are summed to the solar time and is presented in equation 4 .

$$
\omega=(\text { solar time }-12) \cdot 15^{\circ}
$$

Where, $\omega$ is the solar angle in relation to the surface.

The hours of solar irradiation vary for each day of the year, and behaves differently from the hemisphere to which it refers.

From this calculation, it is possible to find out the moment when the sun sets at each day. This paper focus on Brazil, consequently on the Southern hemisphere, thus equation 5 presents the sunset angle calculation for Southern locations [9].

$$
w p s=\min \left[\begin{array}{c}
\cos (-\tan \varphi \cdot \tan \delta)^{-1} \\
\cos (-\tan (\varphi+\beta) \cdot \tan \delta)^{-1}
\end{array}\right]
$$

Where, wps is the sunset angle, $\varphi$ the latitude and $\beta$ the module angle in relation to the terrestrial surface.

\section{B. Solar irradiation on a terrestrial surface}

According to [5], the average hourly irradiation incident on a horizontal surface is the sum of three irradiations: direct, diffuse and albedo, then multiplied by a conversion factor, shown in equation 6.

$$
\begin{aligned}
\text { It. }=\text { Idir } \cdot \text { Rdir. }+ \text { Idif } & \cdot\left(\frac{1+\cos \beta}{2}\right)+ \\
& + \text { Ialb } \cdot 0,2 \cdot\left(\frac{1-\cos \beta}{2}\right)
\end{aligned}
$$

Where, It. is the total irradiation, Idir. the direct irradiation, Idif. the diffuse irradiation, Ialb. the albedo irradiation and Rdir. the conversion factor (varies for each hemisphere).

The conversion factor for the Southern hemisphere is shown by equation 7 .

$$
\text { Rdir. }=\frac{\left(\begin{array}{c}
\cos (\varphi+\beta) \cdot \cos (\delta) \cdot \sin (w p s)+ \\
\left(\frac{\pi}{180}\right) \cdot w p s \cdot \sin (\varphi+\beta)
\end{array}\right)}{\left(\begin{array}{c}
\cos (\varphi+\beta) \cdot \cos \delta \cdot \sin (w p s)+ \\
\left(\frac{\pi}{180}\right) \cdot w p s \cdot \sin (\varphi) \cdot \sin (\delta)
\end{array}\right)}
$$

The irradiation data used in the software calculations are shown in Table I [20].

The values from Table I are a monthly average solar irradiation within the Brazilian territory. Therefore, calculations outside Brazil, but with same latitude, may present errors since they disregard the climate characteristics of these regions.
Table I - Direct, diffuse and global horizontal irradiation for a surface in Brazil.

\begin{tabular}{|c|c|c|c|}
\cline { 2 - 4 } \multicolumn{1}{c|}{} & \multicolumn{3}{c|}{ Irradiation (kWh) } \\
\hline Month & Direct & Diffuse & $\begin{array}{c}\text { Global } \\
\text { horizontal }\end{array}$ \\
\hline Jan & 4153 & 2455 & 5588 \\
\hline Feb & 4479 & 2391 & 5695 \\
\hline Mar & 4228 & 2148 & 5177 \\
\hline Apr & 5496 & 1732 & 5062 \\
\hline May & 5872 & 1391 & 4623 \\
\hline Jun & 6049 & 1289 & 4388 \\
\hline Jul & 5969 & 1378 & 4569 \\
\hline Aug & 7061 & 1600 & 5548 \\
\hline Sep & 5005 & 1823 & 5308 \\
\hline Oct & 4688 & 2128 & 5580 \\
\hline Nov & 4158 & 2432 & 5597 \\
\hline Dec & 4228 & 2602 & 5775 \\
\hline
\end{tabular}

If the daily irradiation is summed and divided by the 365 days of a year an annual mean solar irradiation for a surface is obtained. This value is dependent on $\beta$, and for the software calculations is set an accuracy of four decimals digits to $\beta$.

Therefore, the optimum tilt angle $(\beta)$ of the modules installation is that which maximizes the annual mean solar irradiation from equation 6.

\section{Particle Swarm Optimization for the maximization of the solar mean irradiation}

For each installation angle an analysis is made for 365 days of the year, totaling approximately 32 million analyzes performed by the user's computer for only one latitude value.

Problems with large amounts of variables can be solved by metaheuristic methods such as the Particle Swarm Optimization (PSO). As [21] describes, this method is based on the behavior of artificial life (A-life), such as flock of birds, school of fish and mainly the swarm theory. The PSO used for the problem of maximizing the average annual irradiation on a flat surface develops as follows.

Initially the particles are created on a hyperspace, each with a random position value and their velocities at zero. The developers previously set the software to create 100 particles and to run 25 iterations.

The only variable of the problem is the installation angle $(\beta)$, so the particle position values are the values of $\beta$ and are limited to range from 0,0001 to 89,9999 .

Each particle is tested in an evaluation function. In this case, this function represents the annual average solar irradiation. Through two evaluation structures, each particle is rated. The first structure is the best personal value (Pbest), and by comparing the Pbest values, the second structure - the highest Pbest - is considered as the global best (Gbest).

In the second iteration the particles will move on the hyperspace, therefore the position values will change. The new particle velocity is calculated as shown in equation 8 . A Pbest and a Gbest factor influences the velocity and the next position of the particle. 


$$
\begin{array}{r}
v i(t+1)=w \cdot v i(t)+c 1(p i(t)-x i(t))+ \\
+c 2(g(t)-x i(t))
\end{array}
$$

Where, $v i$ is the particle velocity, $w$ the inertia coefficient, $c 1$ the personal acceleration coefficient, $c 2$ the global acceleration coefficient, pi(t) the influence of Pbest e $g(t)$ the Gbest influence.

Equation 9 shows the particle next position as a sum of the current particle position $(x i(t))$ and the new particle velocity obtained from equation 8 .

$$
x i(t+1)=x i(t)+v i(t+1)
$$

In the next iteration, the particle values are tested and the Pbest and Gbest values are updated. This process repeats a number of iterations previously defined (25 for this software). The last iteration achieves the best answer for the problem.

\section{Shading effect analysis}

Due to the series connection of photovoltaic cells in a module, shading in a part of it can significantly decrease its long-term power generation.

The shading effect in photovoltaic systems occurs due to obstacles near the modules. Trees, walls, tall buildings near the installation site or even by the modules themselves when placed at an elevation greater than $0^{\circ}$ and in parallel, as shown in Figure 3.

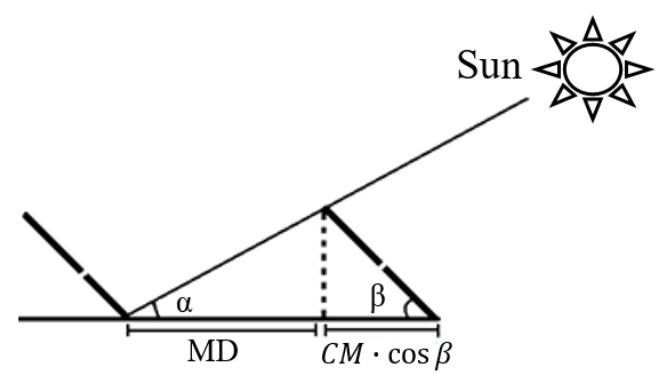

Fig. 3. Parallel module installation scheme.

To fulfill the software purpose of calculating a system without inter-row shading, it is required to know the maximum shadow length to determine the module inter-row spacing.

In this paper, the calculation is made at 7 a.m., since the highest shading happens during the sunrise and, thus the lowest solar height. The solar height is presented by equation 10 [22].

$$
\begin{aligned}
\sigma=\arcsin (\cos \delta \cdot \cos \varphi \cdot & \cos \omega \\
& +\sin \delta \cdot \sin \varphi)
\end{aligned}
$$

Through trigonometrical relations, equation 10 is also described as equation 11 .

$$
\begin{array}{r}
M D=C M \cdot(\cos \beta+\sin \beta \cdot \cot \sigma) \\
-C M \cdot \cos \beta
\end{array}
$$

Where, MD is the minimum distance and CM the length of the module. With MD is possible to calculate the number of modules that fit in the user's installation area.

\section{Software interface}

The software interface is developed in Matlab ${ }^{\circledR}$ and is presented in Figure 4.

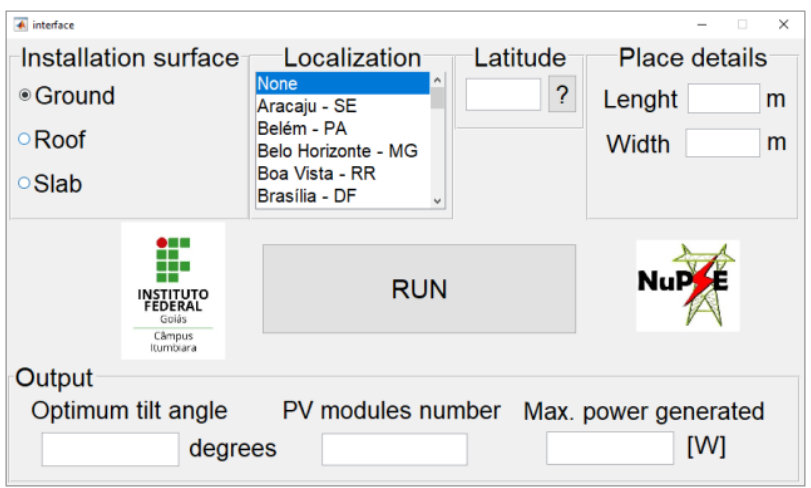

Fig.4. Software interface.

Initially, the installation surface is chosen, with the available options: ground, roof or slab. If the slab option is chosen, the best installation angle values are the closest to the roof slope itself, something usually done by sector companies.

In the "Localization" field the city is chosen. If the user city is not one of the available options selecting the "None" option and typing the place of installation latitude in the "Latitude" field is a possible alternative. A location within Brazil returns better responses.

Then, the characteristics of the installation site are chosen so that the number of photovoltaic solar modules to be installed is defined. The dimensions of the modules are from [17].

Finally, clicking the "RUN" button it starts the calculations. The software will process the information given by the user and then show the best installation angle value in degrees, the number of modules and the maximum power generated in Watts.

\section{Discussion and results}

For all tests presented in tables II and III, the installation surface is "Ground", with the installation area being $50 \times 50 \mathrm{~m}$.

Table II - Tests for latitude: $-18,5^{\circ}$.

\begin{tabular}{|c|c|c|c|}
\hline Test & $\begin{array}{c}\text { Time } \\
(\mathbf{s})\end{array}$ & $\begin{array}{c}\text { Optimum } \\
\text { angle }\left({ }^{\circ}\right)\end{array}$ & $\begin{array}{c}\text { Radiation } \\
(\mathbf{k W h})\end{array}$ \\
\hline $\mathbf{1}$ & 0,0029 & 14,4201 & 3,0791 \\
\hline $\mathbf{2}$ & 0,0010 & 14,4137 & 3,0781 \\
\hline $\mathbf{3}$ & 0,0064 & 14,4245 & 3,0784 \\
\hline $\mathbf{4}$ & 0,0017 & 14,4205 & 3,0790 \\
\hline $\mathbf{5}$ & 0,0010 & 14,4208 & 3,0792 \\
\hline $\mathbf{6}$ & 0,0024 & 14,4184 & 3,0772 \\
\hline $\mathbf{7}$ & 0,0010 & 14,4181 & 3,0750 \\
\hline $\mathbf{8}$ & 0,0008 & 14,4214 & 3,0789 \\
\hline $\mathbf{9}$ & 0,0112 & 14,4210 & 3,0550 \\
\hline $\mathbf{1 0}$ & 0,0013 & 14,4235 & 3,0591 \\
\hline Mean & $\mathbf{0 , 0 0 3 0}$ & $\mathbf{1 4 , 4 2 0 2}$ & $\mathbf{3 , 0 7 3 9}$ \\
\hline
\end{tabular}

All tests were performed on a computer with an Intel ${ }^{\circledR}$ Core $^{\mathrm{TM}}$ i5-5200U CPU with $2,20 \mathrm{GHz}$ of clock, 8GB RAM and Windows ${ }^{\circledR} 10$ operating system.

Table II presents results obtained from ten tests in the software. The average data processing time and the values 
presentation of the optimum tilt angle, number of modules and the maximum generation in the interface is about 0,0030 s.

The values of optimum tilt angle show a slight variation due to the metaheuristic behavior of the PSO. Although the same input settings are used, each output value will differ because the initial particle value is random for each software run.

This small variation does not interfere with the average irradiation values, showing that such precision (four decimal digits) at the time of installation of photovoltaic modules will not necessarily bring a high value of average annual irradiation, and consequently of long term generation.

Table III - Database of the capitals of the states in Brazil.

\begin{tabular}{|c|c|c|c|}
\hline \multicolumn{2}{|l|}{ 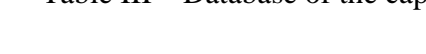 } & \multicolumn{2}{|c|}{ Liu and Jordan } \\
\hline City & $\begin{array}{c}\text { Latitude } \\
\left({ }^{\circ}\right)\end{array}$ & $\begin{array}{c}\text { Optimum } \\
\text { tilt angle }\left({ }^{\circ}\right)\end{array}$ & $\begin{array}{c}\text { Radiation } \\
\text { (kWh) }\end{array}$ \\
\hline Aracaju-SE & $-10,9162$ & 8,4752 & 3,0463 \\
\hline Belém - PA & $-1,4500$ & 1,2080 & 3,0323 \\
\hline Belo Horizonte - $M G$ & $-19,9185$ & 15,5504 & 3,0861 \\
\hline Boa Vista $-R R$ & 2,8208 & 1,7926 & 3,0340 \\
\hline Brasília - DF & $-15,7935$ & 12,2914 & 3,0652 \\
\hline Campo Grande - MS & $-20,4666$ & 15,9942 & 3,0881 \\
\hline Cuiabá - MT & $-15,5987$ & 12,1297 & 3,0498 \\
\hline Curitiba $-P R$ & $-25,4306$ & 20,0336 & 3,1290 \\
\hline Florianópolis - SC & $-27,5973$ & 21,8149 & 3,1489 \\
\hline Fortaleza-CE & $-3,7668$ & 2,9826 & 3,0333 \\
\hline Goiânia-GO & $-16,6805$ & 12,9759 & 3,0630 \\
\hline João Pessoa - PB & $-7,1282$ & 5,5547 & 3,0322 \\
\hline Macapá-AP & 0,0402 & 0,0000 & 3,0326 \\
\hline Maceió - AL & $-9,6522$ & 7,4963 & 3,0394 \\
\hline Manaus - AM & $-3,1330$ & 2,4945 & 3,0324 \\
\hline Natal $-R N$ & $-5,8104$ & 4,5435 & 3,0354 \\
\hline Palmas - TO & $-10,1866$ & 7,9140 & 3,0359 \\
\hline Porto Alegre - RS & $-30,0346$ & 23,8832 & 3,1742 \\
\hline Porto Velho - RO & $-8,7495$ & 6,8025 & 3,0290 \\
\hline Recife-PE & $-8,0729$ & 6,2827 & 3,0375 \\
\hline Rio Branco - AC & $-9,9739$ & 7,7427 & 3,0285 \\
\hline Rio de Janeiro - RJ & $-22,9068$ & 17,9727 & 3,0985 \\
\hline Salvador - BA & $-12,9858$ & 10,0792 & 3,0535 \\
\hline São Luís - MA & $-2,5635$ & 2,0585 & 3,0326 \\
\hline São Paulo - SP & $-23,5487$ & 18,4763 & 3,1080 \\
\hline Teresina - PI & $-5,0896$ & 3,9917 & 3,0344 \\
\hline Vitória - ES & $-20,3201$ & 15,8768 & 3,0901 \\
\hline
\end{tabular}

Table III shows the latitude mapping, optimum tilt angle and annual average irradiation of all state capitals in Brazil and the federal district.

The number of modules varies from 598 with $248 \mathrm{~kW}$ of generation in Belém-PA to 667 with $267 \mathrm{~kW}$ of generation for the cities of Curitiba-PR and Florianópolis-SC.

From the results, it is analyzed that the method described by [5] tends to increase the irradiation values for locations with a higher latitude value (e.g. Porto Alegre-RS and São PauloSP).

Meanwhile, it has some difficulty in predicting the incident irradiation in areas closer to the equator (e.g. Macapá - AP). The data used in Table I are average values for the whole country of Brazil, thus the irradiation values tend to approximate, and consequently bring greater inaccuracy to the forecasts.

According to the Brazilian Solar Energy Atlas [23], the areas with the highest photovoltaic potential in Brazil (red areas) start near the Brazilian capital, going through the northwest of the state of Minas Gerais, west of Bahia, then going to the coast of the states of Piauí, Ceará and Rio Grande do Norte, as shown in figure 6.

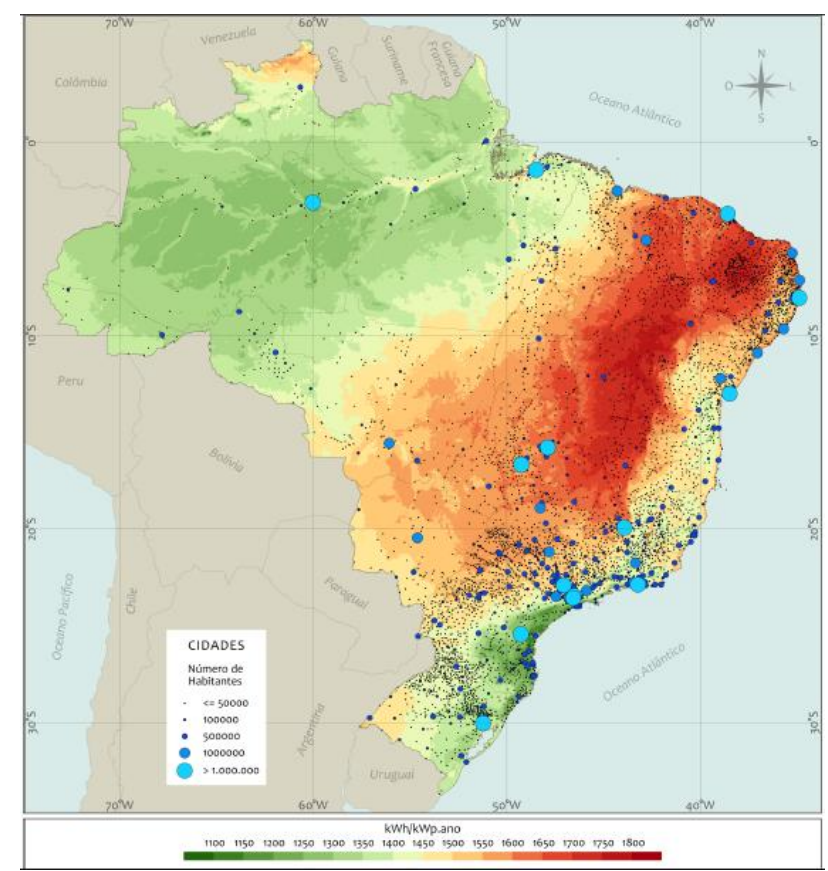

Fig. 6. Photovoltaic power potential

Compared to the values returned by the developed software, it is observed that the method described by [5], although more complex if compared to extraterrestrial solar radiation [24], is still very simple and far from the actual behavior of incident irradiation on terrestrial surfaces.

The commonly used Liu-Jordan isotropic-sky insolation model provides a good fit to empirical data at low intensity conditions found during overcast skies, but underestimates the amount of solar radiation falling on tilted surfaces at intensity levels about $50 \mathrm{~mW} / \mathrm{cm}^{2}$ [6].

Since the average radiation in a module depends on factors such as weather, number of cloudy days in the year, shading and module dirt accumulation, identifying the best installation angle is specific to each location.

Therefore, both the latitude and climate condition should be considered for calculation of the optimum tilt angle [25].

As for the usability of the software, it fulfills its role of predicting what would be the best installation angle of photovoltaic solar modules, the number of modules and the maximum generation, using only simple data from the user.

The user-friendly interface quickly returns helpful responses for the installation of a new solar farm at any latitude of the Southern hemisphere.

\section{Conclusion}

The developed software returns through the latitude angle and site characteristics, the value of the best installation 
angle of photovoltaic modules using the Liu and Jordan method, the number of modules and the maximum generation.

The Particle Swarm Optimization (PSO) is useful for situations where a large amount of analysis and problem variables are present, thus reducing the computational time required converging to the number that maximizes the irradiation function.

The software also fulfills its goal of delineating a photovoltaic system without any shading between strings, but to make this possible, there is a significant decrease in the area available for the modules, which causes a reduction in the total amount of modules in that area.

Regarding the values of angle and solar irradiation, it is demonstrated that there is no need for great accuracy (four decimal digits) in the installation, because the difference in radiation, and consequently, generation will not be large in the long-term.

As the radiation data used refers to Brazil, the software has inaccuracies in locations outside this area. Furthermore, it is concluded that the prediction of the best installation angle is an approximation and a study should be done for each location taking into account variables such as weather and number of cloudy days.

\section{References}

[1] IEA (2019), "Tracking Power", IEA, Paris https://www.iea.org/reports/tracking-power-2019. [Accessed: 18- Dec- 2019].

[2] "EU Market Outlook for Solar Power 2019-2023 - SolarPower Europe", SolarPower Europe, 2019. [Online]. Available: https://www.solarpowereurope.org/global-market-outlook2019-2023/. [Accessed: 23- Dec- 2019].

[3]"BIG - Banco de Informações de Geração", ANEEL, 2019. [Online]. Available: http://www2.aneel.gov.br/aplicacoes/capacidadebrasil/Opera caoCapacidadeBrasil.cfm. [Accessed: 22- Jun- 2019].

[4] M. Sekitou, K. Tanaka and S. Managi, "Household electricity demand after the introduction of solar photovoltaic systems", Economic Analysis and Policy, vol. 57, pp. 102-110, 2018. Available: 10.1016/j.eap.2017.04.001.

[5] B. Liu and R. Jordan, "The long-term average performance of flat-plate solar-energy collectors", Solar Energy, vol. 7, no. 2, pp. 53-74, 1963. Available: 10.1016/0038-092x(63)90006-9.

[6] T. Klucher, "Evaluation of models to predict insolation on tilted surfaces", Solar Energy, vol. 23, no. 2, pp. 111-114, 1979. Available: $10.1016 / 0038-092 \times(79) 90110-5$.

[7] R. Temps and K. Coulson, "Solar radiation incident upon slopes of different orientations", Solar Energy, vol. 19, no. 2, pp. 179-184, 1977. Available: 10.1016/0038-092x(77)900561.

[8] R. Perez, R. Seals, P. Ineichen, R. Stewart and D. Menicucci, "A new simplified version of the perez diffuse irradiance model for tilted surfaces", Solar Energy, vol. 39, no. 3, pp. 221-231, 1987. Available: 10.1016/s0038-092x(87)80031-2.

[9] A. Yadav and S. Chandel, "Tilt angle optimization to maximize incident solar radiation: A review", Renewable and Sustainable Energy Reviews, vol. 23, pp. 503-513, 2013. Available: 10.1016/j.rser.2013.02.027.

[10] J. Kaldellis and D. Zafirakis, "Experimental investigation of the optimum photovoltaic panels' tilt angle during the summer period", Energy, vol. 38, no. 1, pp. 305-314, 2012. Available: 10.1016/j.energy.2011.11.058.

[11] D. Li and T. Lam, "Determining the Optimum Tilt Angle and Orientation for Solar Energy Collection Based on Measured
Solar Radiance Data", International Journal of Photoenergy, vol. 2007, pp. 1-9, 2007. Available: 10.1155/2007/85402.

[12] A. Gharakhani Siraki and P. Pillay, "Study of optimum tilt angles for solar panels in different latitudes for urban applications", Solar Energy, vol. 86, no. 6, pp. 1920-1928, 2012. Available: 10.1016/j.solener.2012.02.030.

[13] Y. Chang, "Optimal the tilt angles for photovoltaic modules using PSO method with nonlinear time-varying evolution", Energy, vol. 35, no. 5, pp. 1954-1963, 2010. Available: 10.1016/j.energy.2010.01.010.

[14] M. Guo et al., "Optimal Tilt Angle and Orientation of Photovoltaic Modules Using HS Algorithm in Different Climates of China", Applied Sciences, vol. 7, no. 10, p. 1028, 2017. Available: 10.3390/app7101028.

[15] CRESESB. Energia Solar Fotovoltaica. Accessed on: Jun. 03, $2019 . \quad$ Available: http://www.cresesb.cepel.br/index.php?section=com_conte nt\&lang $=$ pt\&cid $=321$.

[16] Peroza, J.; Rampinelli, G. Análise de desempenho e atuação de diodos de bypass em um módulo fotovoltaico comercial; VII Congresso Brasileiro de Energia Solar, Rio Grande do Sul, 2018.

[17] CanadianSolar, Módulo Hiku. Accessed on: May 05, 2019. Available: https://www.canadiansolar.com/in/solarPanels/detail/18

[18] F. Padoan, P. Altimari and F. Pagnanelli, "Recycling of end of life photovoltaic panels: A chemical prospective on process development", Solar Energy, vol. 177, pp. 746-761, 2019. Available: 10.1016/j.solener.2018.12.003.

[19] P. Cooper, "The absorption of radiation in solar stills",Solar Energy, vol. 12, no. 3, pp. 333-346, 1969. Available: 10.1016/0038-092x(69)90047-4., 1969.

[20] Sistema de Organização Nacional de Dados Ambientais (SONDA), Base de dados. [Online]. Available: http://sonda.ccst.inpe.br/basedados/index.html. [Accessed: 05- May- 2019].

[21] Eberhart, R.; Kennedy, J.; A new optimizer using particle swarm theory; Sixth International Symposium on Micro Machine and Human Science, IEEE, 1995.

[22] Vitorino, D.; Tapia, G. Análise do sombreamento entre painéis fotovoltaicos. VII Congresso Brasileiro de Energia Solar, Rio Grande do Sul.

[23] LABREN/CCST/ INPE, "Atlas Brasileiro de Energia Solar - 2 ed., " São José dos Campos: INPE, 2017.

[24] H. Zheng, "Solar Energy Utilization and Its Collection Devices," in Solar Energy Desalination Technology. Beijing: Elsevier Inc., 2017, ch. 2, pp. 47-171.

[25] A. Gharakhani Siraki and P. Pillay, "Study of optimum tilt angles for solar panels in different latitudes for urban applications", Solar Energy, vol. 86, no. 6, pp. 1920-1928, 2012. Available: 10.1016/j.solener.2012.02.030. 